\title{
Exploring evapotranspiration dynamics over Sub-Sahara Africa
} $(2000-2014)$

\author{
Christopher E. Ndehedehe ${ }^{\mathrm{a}, \mathrm{b}, *}$, Onuwa Okwuashic ${ }^{\mathrm{c}}$, Vagner G. Ferreira ${ }^{\mathrm{d}}$, Nathan O. Agutu ${ }^{\mathrm{b}}$ \\ ${ }^{a}$ Australian Rivers Institute and Griffith School of Environment $\mathcal{G}$ Science, Griffith University, Nathan, \\ Queensland 4111, Australia. \\ ${ }^{b}$ Department of Spatial Sciences, Curtin University, Perth, Western Australia, Australia. \\ ${ }^{c}$ Department of Geo-Informatics and Surveying, University of Uyo, P.M.B. 1017, Uyo, Nigeria. \\ ${ }^{d}$ School of Earth Sciences and Engineering, Hohai University, Nanjing, China
}

\section{Abstract}

Monitoring changes in evapotranspiration (ET) is useful in the management of water resources in irrigated agricultural landscapes and in the assessment of crop stress and vegetation conditions of drought vulnerable regions. Information on the impacts of climate variability on ET dynamics is profitable in developing water management adaptation strategies. Such impacts however, are generally unreported and not conclusively determined in some regions. In this study, changes in MODIS (Moderate Resolution Imaging Spectroradiometer)-derived ET (2000 - 2014) over large proportions of Sub-Sahara Africa (SSA) are explored. The multivariate analyses of ET over SSA showed that four leading modes of observed dynamics in ET, accounting for about $90 \%$ of the total variability emanated mostly from some sections of the Sudano-Sahel and Congo basin. Based on Man-Kendall's statistics, significant positive trends $(\alpha=0.05)$ in ET over the Central African Republic and most parts of the Sahel region were observed. Over much of the Congo basin nonetheless, ET showed significant $(\alpha=0.05)$ distributions of widespread negative trends. These trends in ET were rather found to be consistent with observed changes in model soil moisture but not in all locations, perhaps due to inconsistent trends in maximum rainfall and land surface temperature. However, the results of spatio-temporal drought analysis confirm that the extensive ET losses in the Congo basin were somewhat induced by soil moisture deficits. Amidst other prominent drivers of ET, the dynamics of ET over the terrestrial ecosystems of SSA appear to be a more complex phenomenon that may transcend natural climate variations.

Keywords: Evapotranspiration, Rainfall, Drought, Temperature, Sub-Sahara Africa, Soil Moisture

*Author now at Australian Rivers Institute, Griffith University, Nathan, Queensland 4111, Australia Email address: christopherndehedehe@gmail.com (Christopher E. Ndehedehe) 


\section{Introduction}

As an essential component of the water budget, evapotranspiration (ET) has been recognised as a primary determinant of water availability together with precipitation, either in terms of groundwater recharge and surface runoff or in the exchanges of energy and mass between the atmosphere, hydrosphere, and biosphere (Andam-Akorful et al., 2015; Long et al., 2014; Liu et al., 2013; Gowda et al., 2008). ET is a well known consumer of irrigation water and precipitation on cultivated land surface that returns more than $60 \%$ of total precipitation on land back to the atmosphere (Mu et al., 2011; Jung et al., 2010; Gowda et al., 2008). On the one hand, ET acts as a connection between the land surface part of the hydrological cycle and the atmosphere (Schüttemeyer et al., 2007). On the other hand, its variability, when properly monitored can be used to support and manage water resources in irrigated agricultural areas and landscapes more efficiently (Li et al., 2017), and assess vegetation conditions of drought-vulnerable regions (Tadesse et al., 2015).

For terrestrial ecosystems with intensive agricultural activities, the relationship of ET with other hydrological quantities (e.g., groundwater and soil moisture) can be used to understand and improve our knowledge of the water cycle. For example, besides the combined effects of energy supply, water storage, and human impacts, the long term decline of rainfall in the North China Plain was presented as a substantial trigger of the observed decline in ET (Cao et al., 2014). ET has been recommended as a critical input for agricultural drought monitoring and a tool for early warning of food insecurity during drought years (Tadesse et al., 2015). Therefore, understanding the variations of ET (inter-annual and seasonal) over rain-fed agricultural landscapes is vital as it could help identify knowledge gaps and research needs that will promote a better understanding of the water cycle and interactions of the land surface with the atmosphere and climate.

In Sub-Sahara Africa (SSA, Fig. 1a) where agriculture is heavily and predominantly reliant on rainfall, we have little knowledge about the spatial dynamics in ET despite being a significant part of the terrestrial water cycle. Unarguably, ET varies across landscapes due to land surface characteristics, soil moisture availability, vegetative cover, hydro-climatic differences, and atmospheric relative humidity amongst others. This variability, which impacts on the regional water cycle and water availability can also remotely or directly impact crop yield and in turn alter food security status. However, studies on ET dynamics in the region are limited and largely undocumented. Although the information of climate change impacts on ET dynamics is useful in developing water management adaptation strategies, Abtew and 
Melesse (2013) argues generally that such impacts however, have not been conclusively determined. Obviously, the limited network of stations to monitor ET globally and regionally due to high cost of direct measurement and surface diversity, have made it difficult to estimate ET at large spatial scales (Cao et al., 2014; Long et al., 2014; Opoku-Duah et al., 2008), hence the poor understanding of climate variations on its evolutions. Regular observations of spatial and temporal dynamics of ET are important and will strengthen our knowledge base of water and energy balance in the region. Because of the lack of considerable investments in ET gauge measurements for hydro-meteorological applications, some large scale ET studies recoursed to the use of remote sensing data and outputs from hydrological models (Andam-Akorful et al., 2015; Schüttemeyer et al., 2007; Marshall et al., 2012a).

With an improved ET algorithm to estimate global and regional terrestrial ET using satellite observations, meteorological data, and remote sensing model of transpiration, driven with vegetation indices, the accuracy of ET data has improved greatly (Andam-Akorful et al., 2015; Marshall et al., 2013; Mu et al., 2011; Gowda et al., 2008). A validation study of ET estimates in West Africa (Schüttemeyer et al., 2007) suggests that satellite-derived ET can actually be used to verify meteorological models in data poor regions. In another ET related region-specific case study, Marshall et al. (2012b) reported on the integration of ET with surface reanalysis data to optimise agricultural drought monitoring in Kenya. They stressed the need to also account for atmospheric moisture demand, which is useful in characterising the reproductive phase of crop growth. They further mentioned that declines in ET are consistent with declines in crop yield and can serve as a measure of crop stress. Furthermore, using global land data assimilation system (GLDAS, Rodell et al., 2004) derived ET, Marshall et al. (2012a) examined ET trends over Africa, associating increase in maximum temperature to the observed decline of ET over western Sahel. Given that the enormous landscape of Africa is a web of different physical processes and interactions that affect ecosystem dynamics and water cycle, more studies are required to unmask the evolutions of complex hydrological processes in the region. Identifying ET drivers and understanding its seasonal distributions and variations in relation to other hydrological indicators (e.g., soil moisture), for example, could provide further perspectives on the region's water cycle and land-atmosphere coupling.

In this contribution, an attempt is made to understand the regional dynamics and trajectories of ET during the 2000 - 2014 period by analysing ET over large proportions of SSA using cumulant-based multivariate techniques (Cardoso, 1999; Cardoso and Souloumiac, 1993) and Man-Kendall's statistics. Contrary to previous studies, the spatial and temporal dynamics 
of ET are localised in the region using this multivariate technique. The specific aims of this study are, to (i) identify the leading modes of ET and understand its dynamics in the region and (ii) examine the impacts of soil moisture deficits on ET dynamics in the region.

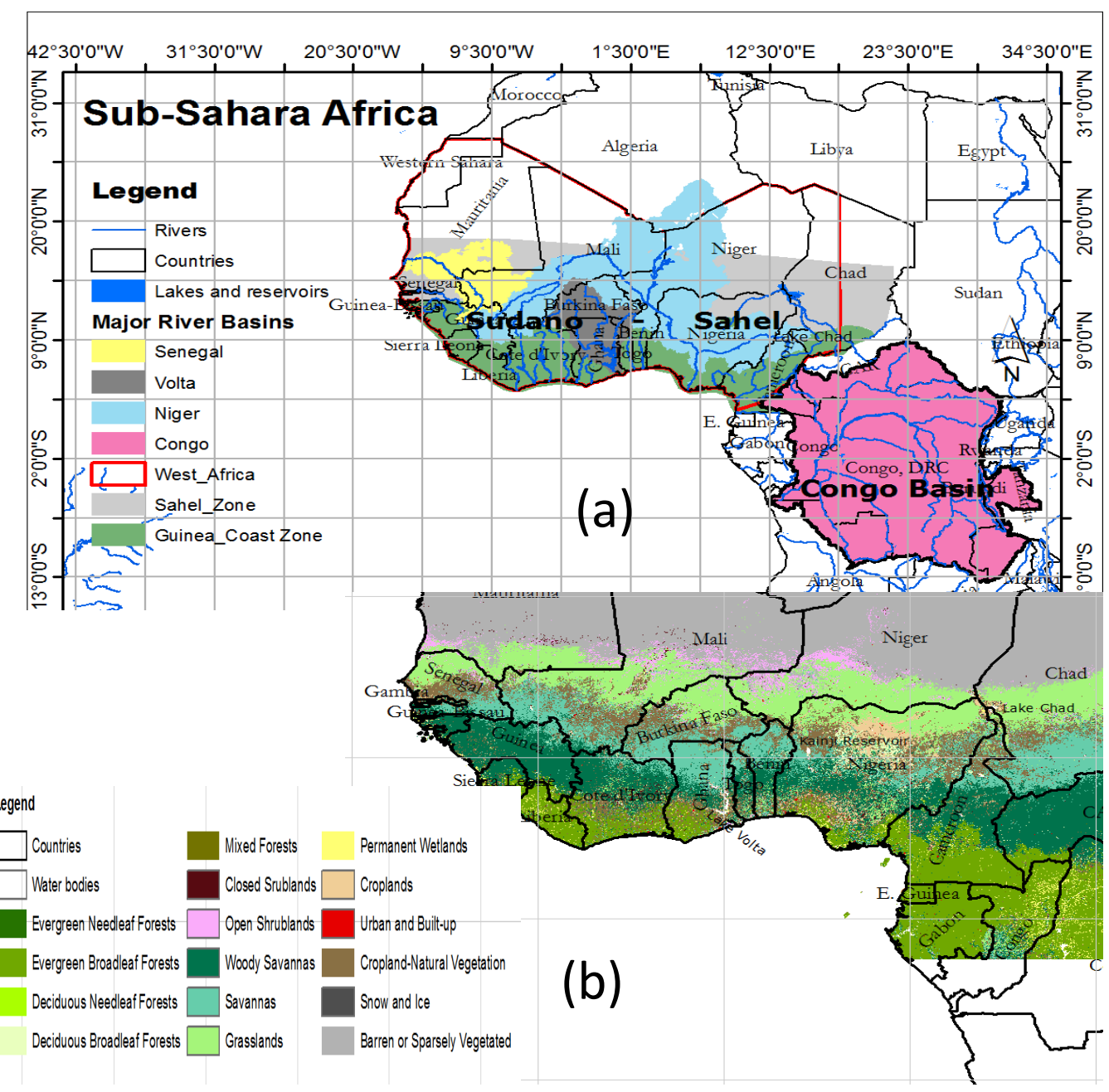

Figure 1: Study area showing (a) some countries in the SSA region, major river basins, climatic zones, and water fluxes (map is modified from Ndehedehe et al. (2017b). (b) The distribution of land cover units over West Africa and some parts of the Congo basin that constitutes SSA. The land cover map was obtained from MODIS (MCD12Q1) Land Cover products processed by the Land Processes Distributed Active Archive Center (available at http://webmap.ornl.gov/ogcdown/dataset.jsp?ds_id=10004).

\section{Materials}

\subsection{MODIS global terrestrial evapotranspiration project}

This study used the improved version of MODIS (Moderate Resolution Imaging Spectroradiometer) global terrestrial evapotranspiration (ET) products by $\mathrm{Mu}$ et al. (2011). Although there are other ET estimates based on an improved version of a process-based biogeochemistry 
model, Terrestrial Ecosystem Model (Liu et al., 2013, 2014), we have used Mu et al. (2011) MODIS global ET product. This is because Andam-Akorful et al. (2015) recently reported that MODIS-derived ET estimations over the Volta basin in the region represented relatively lower magnitude of uncertainties ( $3.99 \mathrm{~mm} / \mathrm{month}$ ) compared to Global Land Data Assimilation System (GLDAS)-NOAH (Rodell et al., 2004) and terrestrial water budget (TWB)-based ET estimations, which indicated 7.06 and $18.85 \mathrm{~mm} / \mathrm{month}$, respectively, in the magnitude of their uncertainties. On the error structure of ET models, vegetation indices and flux magnitudes have been identified as significant drivers of model error (Polhamus et al., 2013). The total global annual ET as estimated over vegetated land surface using the improved MODIS-derived ET of $\mathrm{Mu}$ et al. (2011) showed better agreement with previous estimates of ET over the terrestrial land surface. To this end, we analysed the spatio-temporal variability of ET over SSA using the MODIS-derived ET product of Mu et al. (2011). This monthly ET data has a spatial resolution of $0.5^{\circ} \times 0.5^{\circ}$ and covers the period between 2000 and 2014. The data is available for download at the Earth Observing System of NASA's website (http://www.ntsg.umt.edu/project/mod16).

\subsection{Tropical Rainfall Measuring Mission (TRMM) based precipitation}

TRMM (Kummerow et al., 2000) provides monthly precipitation estimates of high spatial resolution $\left(0.25^{\circ} \times 0.25^{\circ}\right)$ product called $3 \mathrm{~B} 43$, covering $50^{\circ} \mathrm{S}$ to $50^{\circ} \mathrm{N}$. For this study, monthly TRMMv7 3B43 precipitation rates from National Aerospace and Space Administration (NASA) Goddard Space Flight Center (GSFC, www.mirador.gsfc.nasa.gov) covering the period between 1998 and 2013 is used to analyse the relationship between rainfall and ET over West Africa. TRMM shows good agreement with the Global Precipitation Climatology Center (GPCC) gauge data over West Africa (i.e., area comprising most countries of SSA) (Ndehedehe et al., 2016a; Thiemig et al., 2012). Further, the monthly TRMM precipitation was resampled into $0.5^{\circ} \times 0.5^{\circ}$ in order to ensure a common spatial resolution with ET. This is important for consistency as correlations between TRMM-precipitation and ET was spatial or grid based.

\subsection{Climate Prediction Center (CPC) Soil Moisture}

Evapotranspiration is limited by soil moisture availability (Jung et al., 2010). To examine such impacts over SSA, this study employed monthly CPC model soil moisture data (Fan and Dool, 2004) with spatial resolution of $0.5^{\circ} \times 0.5^{\circ}$ for the common period as ET. The data is freely available at NOAA's website for download (www.esrl.noaa.gov/psd/data/gridded/data. 
cpcsoil.html). To explore the relationships between observed drought patterns and ET dynamics, the data was used to construct standardised soil moisture index (SSMI) for the period during 1979 - 2013 by employing a 6 month aggregation scale, which is rather suitable to monitor agricultural drought (Agutu et al., 2017; Ndehedehe et al., 2016b). The model soil moisture data for the period during 2000 - 2014 consistent with ET was also analysed to understand the distribution of spatial trends in soil water over SSA.

\subsection{Land surface temperature}

The land surface temperature component of Global Land Data Assimilation System (GLDAS, Rodell et al., 2004) data used in this study was obtained from the Goddard Earth Sciences Data and Information Services Center (GESDICS). GLDAS uses data assimilation techniques to generate series of land surface state. The monthly land surface temperature with spatial resolution of $1.0^{\circ} \times 1.0^{\circ}$ used in this study was derived from the CLM component of GLDAS. In the presence of moisture, evapotranspiration depends basically on the solar energy available to vaporize the water from plants and soil (Hanson, 2013). Therefore, the data covering the years 2000 - 2014 was used to study the impacts of land surface temperature on ET dynamics over SSA.

\subsection{Terrestrial water storage from Gravity Recovery and Climate Experiment (GRACE)}

The GRACE (Tapley et al., 2004) satellite mission provides changes in terrestrial water storage-TWS (sum total of changes in groundwater, soil moisture, surface waters and canopy) based on observations of the Earth's time variable gravity fields. The GRACE Release-05 (RL05) spherical harmonic coefficients from the Center for Space Research (CSR, http://icgem.gfz-potsdam.de/ICGEM/shms/monthly/csr-rl05/degree60/), truncated at degree 60, covering the period between 2002 and 2014 were used in the study to estimate TWS. The approaches from previous studies (Landerer and Swenson, 2012; Fenoglio-Marc et al., 2012; Ndehedehe et al., 2016a) were followed in the processing of spherical harmonic coefficients and post processing of computed equivalent water heights as they are only briefly mentioned here. The land water-storage expressed in terms of equivalent water heights (hereafter called TWS) were computed on a $1^{\circ} \times 1^{\circ}$ grid from the filtered monthly GRACE-solutions following the method of Wahr et al. (1998):

$$
\triangle T(\phi, \lambda, t)=\frac{R \rho_{\text {ave }}}{3 \varrho_{w}} \sum_{l=0}^{l_{\max }} \frac{2 l+1}{1+k_{l}} \sum_{m=-l}^{l} P_{l m}(\phi, \lambda) \triangle Y_{l m}(t)
$$


where $\triangle T$ is the variations in TWS for each month in time $(t)$, and where $\phi, \lambda$ are latitudes and longitudes, respectively. $\mathrm{R}$ is the radius of the Earth taken to be $6378.137 \mathrm{~km}, \rho_{\text {ave }}$ is the average density of the Earth $\left(5515 \mathrm{~kg} / \mathrm{m}^{3}\right), \varrho_{w}$ is the average density of water $\left(1000 \mathrm{~kg} / \mathrm{m}^{3}\right), k_{l}$ is the load Love numbers of degree $l, P_{l m}$ are the normalized associated Legendre functions of degree $l$ and order $\mathrm{m}$ with $l_{\max }=60$ and $\triangle Y_{l m}$ are the normalized complex spherical harmonic coefficients after subtracting the long term mean. Since inception, GRACE-derived TWS has been employed in several hydrological applications as summarised by Wouters et al. (2014) and is gradually emerging as a tool for ecosystem assessment and climate studies in Africa and other regions (Ndehedehe et al., 2018a,b, 2017b; Abiy and Melesse., 2017; A et al., 2015; Yang et al., 2014).

\section{Methods}

\subsection{Regionalization of evapotranspiration}

The independent component analysis (ICA, Cardoso, 1999; Cardoso and Souloumiac, 1993) is an advanced multivariate, fourth order statistical method that explores the hidden dynamics of a given system through the rotation of its principle components towards independence. Due to its computational efficiency and improved skill in signal decomposition (Cardoso, 1999), the ICA method has been employed in analysing GRACE-derived TWS (Ndehedehe et al., 2017a,b; Boergens et al., 2014; Awange et al., 2014; Frappart et al., 2011) and to localize drought signals (Ndehedehe et al., 2016b,c). As it was mentioned in Ndehedehe et al. (2017b), the interest in regionalizing hydro-climatic signals at global and basin scale is increasing and has resulted in the applications of ICA in geophysical signal separation, regionalisation of hydrological data, and drought characterisation. In this study, the Joint Approximate Diagonalisation of Eigen matrices (JADE) ICA algorithm fully documented by Cardoso and Souloumiac (1993) and Cardoso (1999) was used to regionalize (i.e., decompose into independent temporal and spatial patterns) ET over SSA. The leading orthogonal modes that explain the most variability in the dataset, $\mathbf{x}$ were first identified using the empirical orthogonal function analysis (EOF, Hannachi et al., 2007; Hendricks et al., 1996) method as

$$
\mathbf{P}_{i}=\mathbf{e}_{i j} \mathbf{x}_{j}
$$

where $\mathbf{P}_{i}$ are linear combinations of $\mathbf{x}$ while $\mathbf{e}_{i j}$ are the set of empirical orthogonal functions (EOFs). Projecting the data $\mathbf{x}$ onto the EOFs we obtain the principal components (PCs) $\mathbf{P}_{i}$, which can be expressed as (Ndehedehe et al., 2016a) 


$$
\begin{gathered}
P_{i, 1}=e_{11} \mathbf{x}_{1}+e_{12} \mathbf{x}_{2}+e_{13} \mathbf{x}_{3}+\ldots+e_{1 k} \mathbf{x}_{i, k} \\
P_{i, 2}=e_{21} \mathbf{x}_{1}+e_{22} \mathbf{x}_{2}+e_{23} \mathbf{x}_{3}+\ldots+e_{2 k} \mathbf{x}_{i, k} \\
P_{i, 3}=e_{31} \mathbf{x}_{1}+e_{32} \mathbf{x}_{2}+e_{33} \mathbf{x}_{3}+\ldots+e_{3 k} \mathbf{x}_{i, k} \\
\ldots \\
P_{i, k}=e_{k 1} \mathbf{x}_{1}+e_{k 2} \mathbf{x}_{2}+e_{k 3} \mathbf{x}_{3}+\ldots+e_{k k} \mathbf{x}_{i, k}
\end{gathered} \quad i=1, \ldots, n
$$

$\mathbf{e}_{i j}$ is determine such that $P_{i, 1}$ are the new uncorrelated variables and the expression of the original data in the new coordinate system. $P_{i, 1}$ explains the highest variance of the multivariate data $\mathbf{x}$ while $P_{i, 2}, P_{i, 3}$ up to $P_{i, k}$ explain the possible amount of the remaining variance. The EOF's are spatially orthonormal while the PC's are orthogonal and linearly independent. The statistical significant modes obtained from Eqn. 3 were further rotated and decomposed using the ICA technique as

$$
\mathbf{X}_{p, q}=\mathbf{A}_{j} \mathbf{S}_{j},
$$

where $\mathbf{X}$ comprise the leading orthogonal modes for ET over the study area, $p$ represents the number of months, and $q$ is the number of grid cells (observations). The columns of $\mathbf{A}_{j}$ consists of the dominant temporal evolutions of the hydrological quantities, which are unit-less while the rows of $\mathbf{S}_{j}$ are their corresponding statistically independent spatial patterns. Further helpful theoretical details on this method can be found, for e.g., in Cardoso and Souloumiac (1993), Cardoso (1999), Ziehe (2005), and Ndehedehe et al. (2016b). The derived ICA modes are the combination of the temporal evolutions and the spatial patterns and are jointly interpreted to get the variability in the datasets (i.e., ET).

\subsection{Trends and correlation analysis}

The Sen's slope (Sen, 1968) estimator was used to estimate trends since it is robust and resistant to outliers. Sen slope $\left(S_{i}\right)$ is the median overall values of the whole data and is estimated as

$$
S_{k}=\operatorname{Median}\left(\frac{P_{j}-P_{i}}{j-i}\right), \text { for }(1 \leq i<j \leq n),
$$

where $P_{j}$ and $P_{i}$ represents data values at time $j$ and $i(j>i)$, respectively while $n$ is the number of data. The slope can be positive indicating increasing trend or negative, indicating decreasing trend. The significance of observed trends was tested using the Man-Kendall's test (Mann, 1945; Kendall, 1970), a widely used non-parametric method in testing the significance of trends. The Mann-Kendall statistic $(M)$ is a non-parametric method and is calculated as

$$
M=\sum_{k=1}^{n-1} \sum_{j=k+1}^{n} \operatorname{sgn}\left(P_{j}-P_{i}\right)
$$


where $n$ is the number of data locations. Machiwal and Jha (2012) suggests that even $n$ values as low as 10 can be used in Man-Kendall 's test provided there are no too many tied values. Supposing that $x=P_{j}-P_{i}$, then $\operatorname{sgn}(x)$ is estimated as

$$
\operatorname{sgn}(x)= \begin{cases}1, & \text { if } x>0 \\ 0, & \text { if } x=0 \\ -1, & \text { if } x<0\end{cases}
$$

The $M$ statistic represents the positive and negative differences for all data samples under consideration. The mean of the statistics under the null hypothesis is zero and is given as $\mathrm{E}[\mathrm{M}]=0$ while its variance $(\sigma)$ is given as

$$
\sigma=\frac{n(n-1)(2 n+5)-\sum_{k=1}^{n}\left(t_{j}-1\right)\left(2 t_{j}+5\right)}{18} .
$$

The Man-Kendall test statistics $(M)$ is approximately normally distributed, subject to the following Z-transformation,

$$
Z= \begin{cases}\frac{M-1}{[\sigma]^{1 / 2}}, & \text { if } M>0 \\ 0, & \text { if } M=0 \\ \frac{M+1}{[\sigma]^{1 / 2}}, & \text { if } M<0\end{cases}
$$

The null hypothesis (no trend), $H_{0}$, was tested at $\alpha=0.05$ (95\% confidence level). Also, in order to understand the relationship of ET with TWS and TRMM-based precipitation, the monthly grids of ET were correlated with those of TWS and TRMM for the common period using Pearson correlation $(r)$. The linear correlation between two hydrological quantities is given as;

$$
r_{i j}=\frac{\sigma i j}{\sqrt{\sigma i i \sigma j j}} \in[-1,+1]
$$

where $\sigma i j, \sigma i i$, and $\sigma j j$ are the given covariances between the two hydrological variables. Before the correlation, the gridded ET data was resampled to a $1^{\circ} \times 1^{\circ}$ regular grid as the GRACE-derived TWS while TRMM-based precipitation was resampled to a $0.5^{\circ} \times 0.5^{\circ}$ regular grid as the original ET data in order to ensure consistency in the number of grids sampled for each variable. Also, since ET is a flux and TWS a hydrologic state variable, TWS change (TWSC), which is the approximation of the water mass variations in a particular month $(t)$ as shown in Eqn. 1 was derived from numerical differentiation using the center difference approach as (Ferreira and Asiah, 2015)

$$
\frac{\mathrm{d} T W S C(t)}{\mathrm{d} t} \approx \frac{\triangle T W S(t+\triangle t)-\triangle T W S(t-\triangle t)}{2 \triangle t} .
$$


Thus, the GRACE-derived TWSC was correlated with ET during a common period (2002 2014). The ET-TWSC relationship was considered to examine the potential of TWSC in monitoring the impacts of climate variability on the dynamics of ET.

\subsection{Soil moisture drought index}

Droughts are environmental disasters that affect water fluxes and can result in a range of negative impacts such as reduced water supply, crop failure, reduced range productivity, and disturbed riparian habitats amongst others (Mishra and Singh, 2010). As a follow up to the observed hydrological conditions in the Congo basin, standardised soil moisture index (SSMI) was further employed to evaluate the impact of drought as it relates to the behaviour of observed ET in the region. To this end, similar to standardised precipitation index (SPI, McKee et al., 1993), a distribution function was fitted to the CPC-based soil moisture data for the period of 1979 - 2013. Instead of the usual parametric approach, which uses a gamma distribution, Pearson III distribution, lognormal or any other distribution (Kumar et al., 2015; Mishra and Singh, 2010; Shukla and Wood, 2008), the empirical probability method was used to derive a non-parametric soil moisture standardised index as (Farahmand and AghaKouchak, 2015; Hao and AghaKouchak, 2014):

$$
p\left(x_{j}\right)=\frac{m_{j}-0.44}{n+0.12},
$$

where $n$ is the sample size, $j$ represents the the rank of non-zero soil moisture data starting from the smallest while $p\left(x_{j}\right)$ is the corresponding empirical probability. Eqn 12 is transformed to a standardised index as

$$
S I=\phi^{-1}(\rho)
$$

where $\phi$ is the standard normal distribution function and $\rho$ is the probability obtained from Eqn 12. The SSMI was based on a 6 month aggregation scale since that is more suitable for agricultural drought applications (Ndehedehe et al., 2016b). The SSMI values obtained from Eqn 13 were further decomposed into spatial and temporal patterns using the regionalisation technique described in Section 3.1. This approach optimises drought analysis as it serves as a suitable method that enables the space-time monitoring of drought occurrence (Ndehedehe et al., 2016b,c). The spatial and temporal evolutions of SSMI are interpreted together using the McKee et al. (1993) classification system summarised in Table 1. 
Table 1: Drought classification for soil moisture events based on McKee et al. (1993) classification system.

\begin{tabular}{ll}
\hline Description & Threshold \\
\hline Extreme wet & +2.0 and above \\
Very wet & +1.5 to +1.99 \\
Moderately wet & +1.0 to +1.49 \\
Near normal & -0.99 to +0.99 \\
Moderate drought & -1.0 to -1.49 \\
Severe drought & -1.5 to -1.99 \\
Extreme drought & -2.0 or less \\
\hline
\end{tabular}

\section{Results and discussion}

\subsection{Leading modes of evapotranspiration}

The regionalisation of ET resulted in four leading modes (temporal and spatial patterns), accounting for more than $90 \%$ of the total variability in ET over SSA (Fig. 2). Generally, the observed spatio-temporal variability of ET over SSA emanates mostly from areas that are predominantly savannas, forests, grasslands, agricultural biomes (cf. Fig. 1b), and regions that are well known to be characterised by considerable fluctuations in climate. For example, it is obvious that the dominant variability of ET in SSA, which accounts for about $28 \%$ of the total variability is found in the savannas of West and Central Africa (IC1, Fig. 2). The spatial patterns of IC2 (Fig. 2), which accounts for $22.5 \%$ of the total variability in ET is found in the Congo basin, home to the second-largest rainforests on Earth while the spatial patterns corresponding to IC3 in Fig. 2 are largely cultivated ecosystems and savannas located in the Sahelian countries (cf. Fig. 1b). The evolving temporal patterns associated with the spatial variations of ET (IC1-IC4, Fig. 2) indicate strong annual variations with peak maximum amplitudes that generally seem to be consistent with the well known variability of rainfall in the region. By interpreting the temporal and spatial patterns of ET together (Section 3.1), the lowest observed maximum ET peak occurred in 2004 at southern Chad (IC3, Fig. 2). Although the peak amplitudes of ET at southern Chad in subsequent years were relatively stronger, it is not clear what happened in 2004. However, drought indicators over the Lake Chad basin, where southern Chad is seated indicated moderate and severe droughts between 2004 and 2005 at different aggregation time scales (Ndehedehe et al., 2016b). Whereas ET fell slightly ( -4.0 mm/month/yr) in some segments of the Congo basin (IC2, Fig. 2), coinciding with the long term drying of the Congolese forest (e.g., Zhou et al., 2014), it 

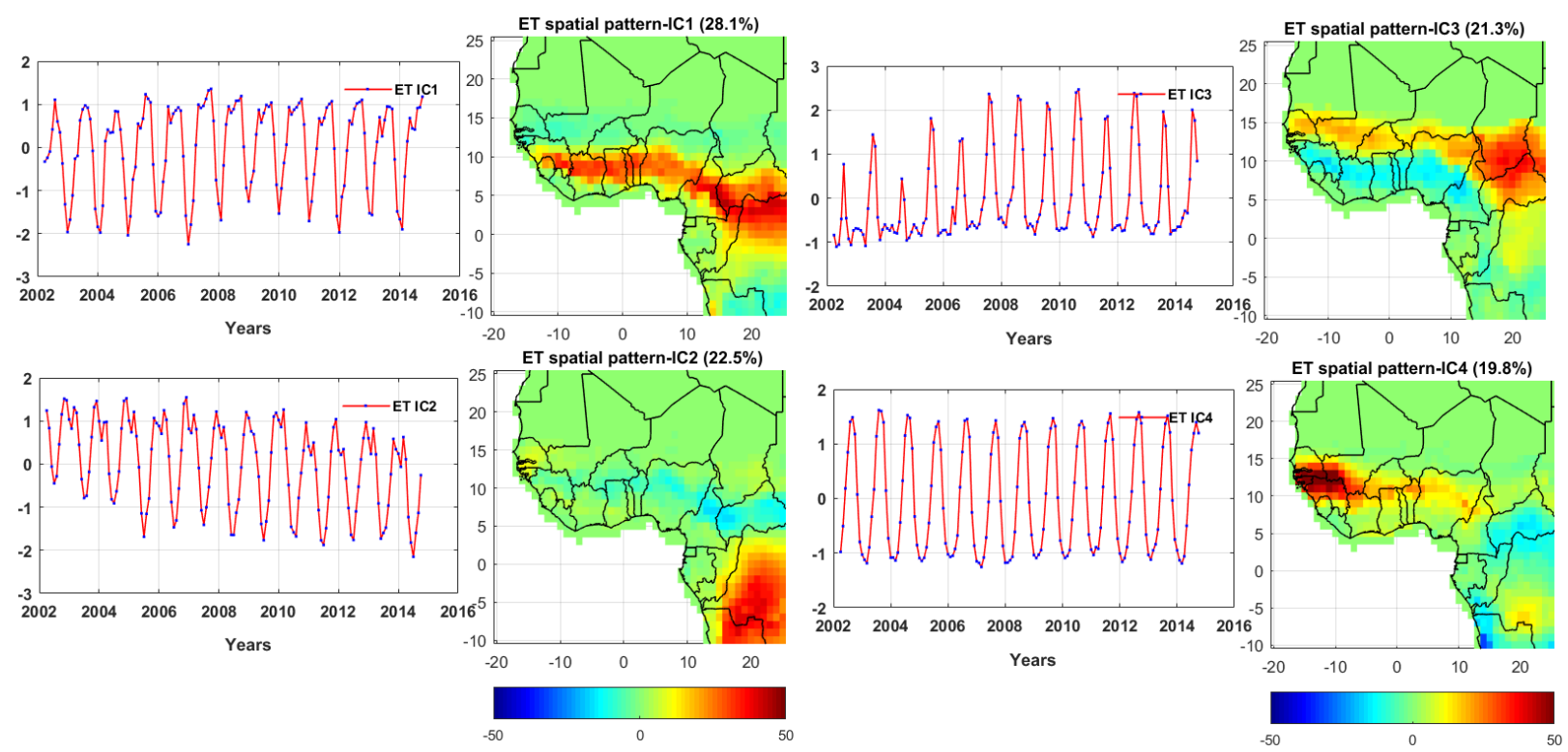

Figure 2: The spatial and temporal dynamics of ET over SSA using the ICA technique. The independent components (ICs) are temporal evolutions (right) corresponding to the spatial patterns (left). These ICs are unit-less since they have been normalised using their standard deviations while the corresponding spatial patterns have been scaled (they have been adjusted to their original units-mm) using the standard deviation of the computed ICs.

increased steadily in southern Chad and over other Sahelian areas after 2004 (IC3, Fig. 2). The temporal evolutions of ET in other regions however, showed no apparent trend (IC1 and IC4, Fig. 2). The spatio-temporal variations of ET in Fig. 2 across SSA are indications of the hydrological diversity in the region, perhaps caused by different physical/environmental processes and climate perturbations amongst others.

\subsection{Evapotranspiration dynamics}

\subsubsection{Spatial trends in ET during the $2000-2014$ period}

Spatial variations of significant $(\alpha=0.05)$ monthly trends in ET show a widespread increase along the Sahel, Central African Republic (CAR), and Gabon while the southern Congo basin is mostly characterised by declines of more than $5 \mathrm{~mm} / \mathrm{month} / \mathrm{yr}$ (Fig. 3a), which is consistent with the results depicted in Fig. 2 (i.e., IC2). The spatial distribution of positive trends in ET during the November-March period when rainfall is relatively low appears to be restricted to only few countries of West Africa, southern Congo, and Gabon (Fig. 3b). On the contrary, the April-October period characterised by heavy rainy seasons in the region show large distributions of increasing ET in the region (Fig. 3c). Overall, be it rainy or dry seasons, significant parts of the Congo basin indicate far-reaching ET loss during the 2000-2014 period 


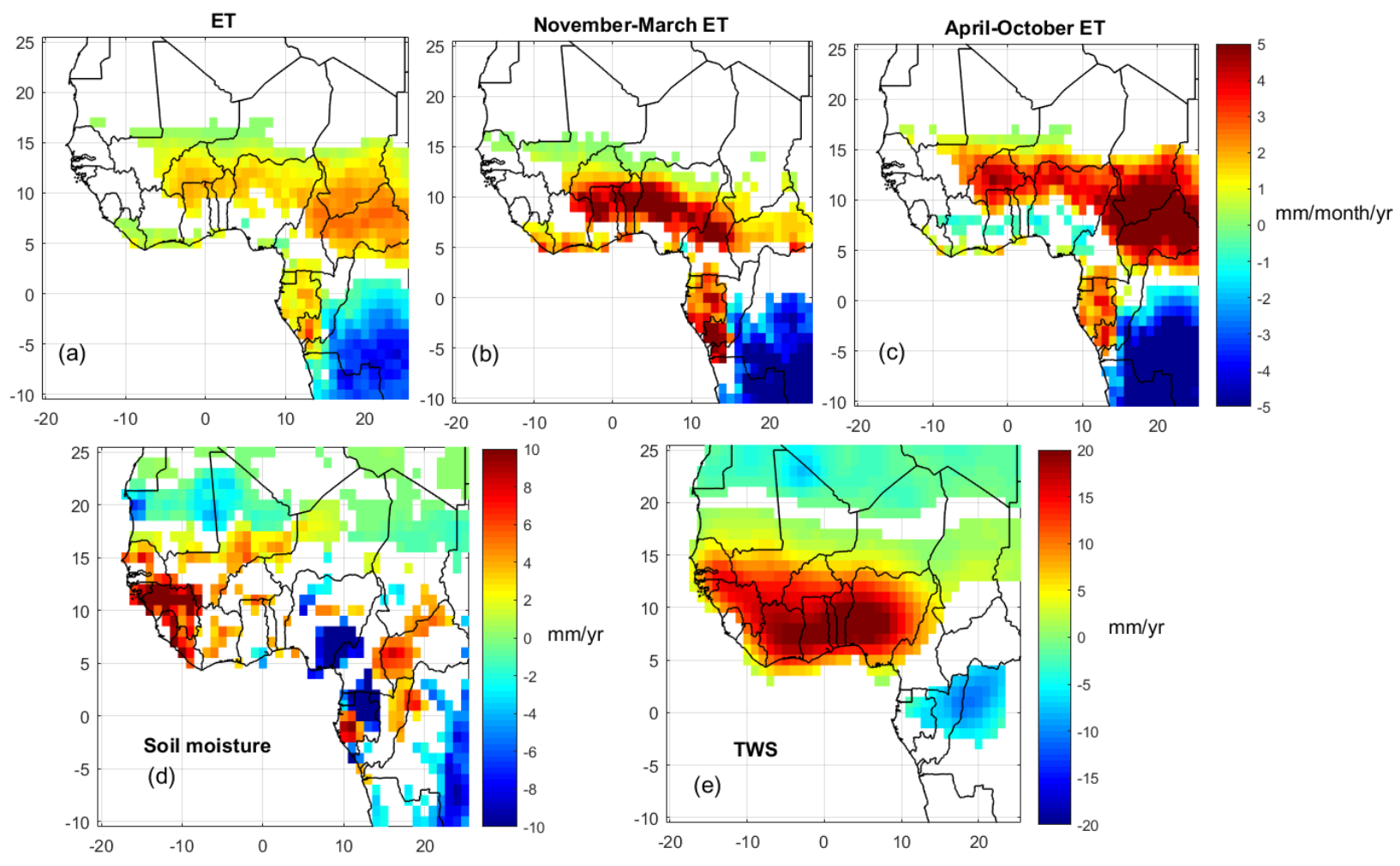

Figure 3: Spatial variations of evapotranspiration and soil moisture trends (2000-2014); and TWS (2002-2014) over SSA. Trends are indicated for (a) all monthly time series of ET, (b) November- March season (c) AprilOctober season, (d) all monthly time series of soil moisture, and (e) all monthly time series of TWS. Only statistically significant trends $(\alpha=0.05)$ during the period are shown.

(Fig. 3a-c). It seems most changes in ET during the period largely occurred during periods when rainfall oscillates strongly as the spatial pattern of ET trends during April-October period (Fig. 3c), though relatively stronger, is similar to observed spatial variations in all monthly time series of ET in Fig. 3a.

Soil moisture is a major driver in the ET process. As ET is known to be driven primarily by soil moisture limitations (Jung et al., 2010), it would be expected that observed evapotranspiration trends will coincide with spatial variations of soil moisture trend (Fig. 3d). Whereas this is true for some locations in CAR and the Congo basin, the spatial distribution of soil moisture trends are significantly inconsistent with those of ET in the region (Figs. 3a and d). For instance, in Guinea and south-east Nigeria where soil moisture showed a considerable increase and decrease, respectively (Fig. 3d), there were no corresponding significant changes in ET (Fig. 3a) during the period. Our understanding of the evapotranspiration process in relation to soil moisture change may be complicated in the Sahel due to some physical properties (e.g., structural stability, crusted soils, and low organic matter contents) of the Sahelian 

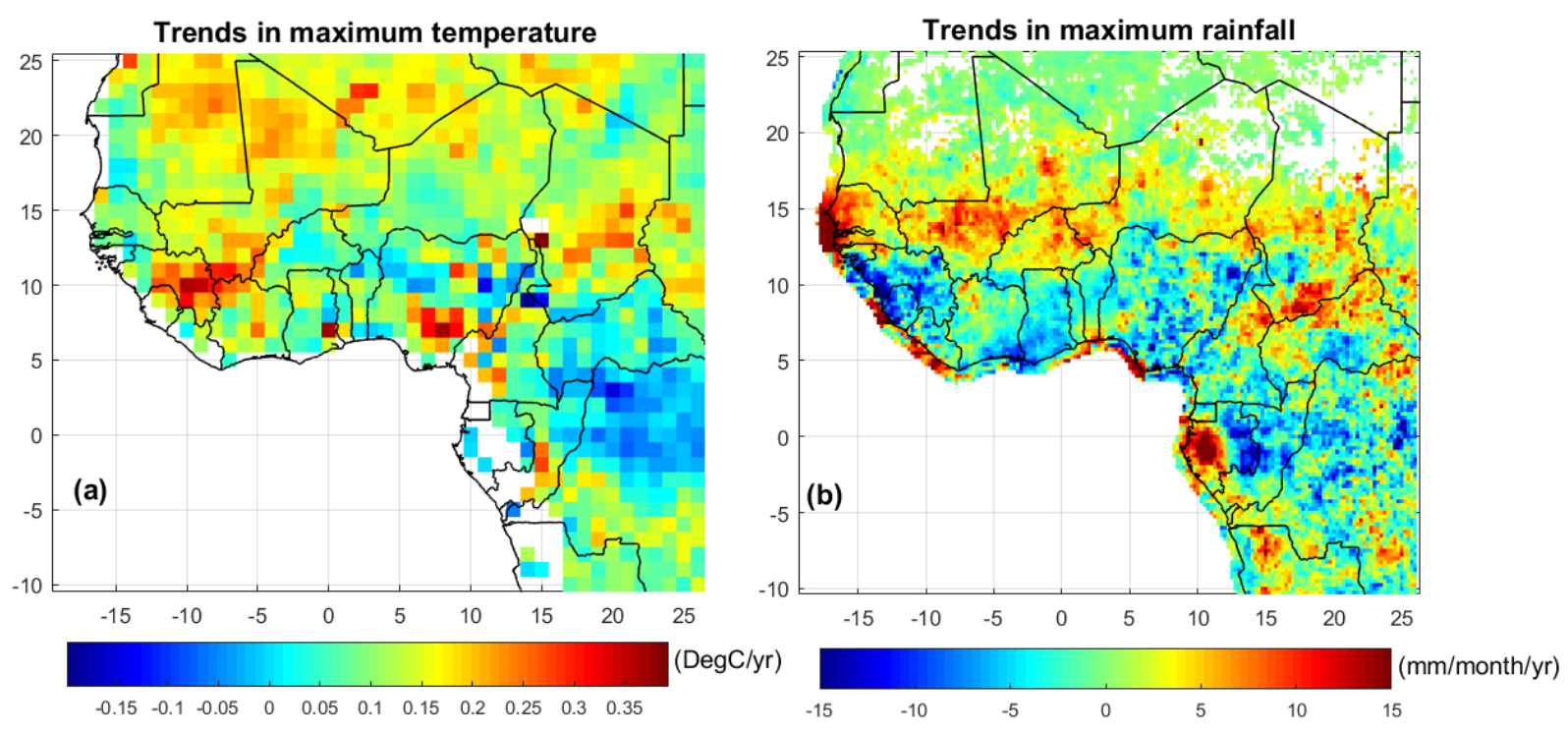

Figure 4: Spatial variation of trends in maximum (a) temperature and (b) rainfall during the $2000-2014$ period. Please note that only statistically significant trends $(\alpha=0.05)$ during the same period $(2000-2014)$ are indicated.

soil as reported by Descroix et al. (2009), and perhaps increased temperature in some areas (Fig. 4a) and strong variability in annual rainfall. It has been argued that rising temperature with a corresponding decrease in rainfall will result in increased ET (Abtew and Melesse, 2013). Again, ET trends in Guinea and southern Nigeria (Fig. 3a) showed otherwise despite decrease in maximum rainfall, which was accompanied by a significant rise in maximum temperature (Figs. 4a and b). Although the spread of spatial trends in rainfall are significantly different from those of ET, there are pockets of positive ET trends however, in some areas where rainfall showed increase (Figs. $3 \mathrm{a}$ and $4 \mathrm{~b}$ ). In such locations, rainfall is likely to be spatially homogenous and climate variability rather low. Thus, a rise in ET can be attributed to increased rainfall, and during periods of prolonged deficits in rainfall, transpiration from existing forests and extensive vegetation cover may also lead to increased ET. For the arid Sahel, which is largely characterised by high spatial variability in rainfall and extreme climatic conditions, the evolutions of ET trends may be inconsistent with rainfall due to a possible high evaporative demand linked to increasing radiative forcing. Generally, it is noted nonetheless, that regions with rising ET (Fig. 3a-c) coincide with drought vulnerable areas and where severe drought events have been reported during the same period (Ndehedehe et al., 2016b,c; Hua et al., 2016). Given that drought periods are characterised by low humidity and clear sky days, which creates advantageous and thriving environment for rising ET (Abtew and Melesse, 2013), moisture limitations in the semi arid Sahel may be a significant driver of changes 
in ET trends. On the flip side, widespread ET declines in the Congo basin are consistent with observed declines in soil moisture and TWS (Figs. 3d and e) despite sparsely distributed positive trends in maximum rainfall in some locations of the basin (Fig. 4b). During the last decade, large parts of the Congo basin experienced massive drying as hydrological conditions have been rather unfavourable (Ndehedehe et al., 2018b; Hua et al., 2016; Zhou et al., 2014; Ahmed et al., 2014). The contributions of climate variables such as rainfall, relative humidity, sunshine duration, wind speed, temperature, and leaf area index, arguably provide considerable influence on ET changes (Song et al., 2017; Cao et al., 2014; Liu et al., 2013). The impact of anthropogenic contributions (e.g., irrigation, deforestation, agricultural expansion, land use change, etc.) on rising and decreasing ET is however, well known (Zou et al., 2017; Han et al., 2017; Cao et al., 2014; Liu et al., 2008), and in some cases such impacts are even considerably higher than those of climate variations (Zou et al., 2017). Overall, changes in ET over the different landscapes of SSA therefore appear to be a more complex phenomenon that transcend natural climate variations.
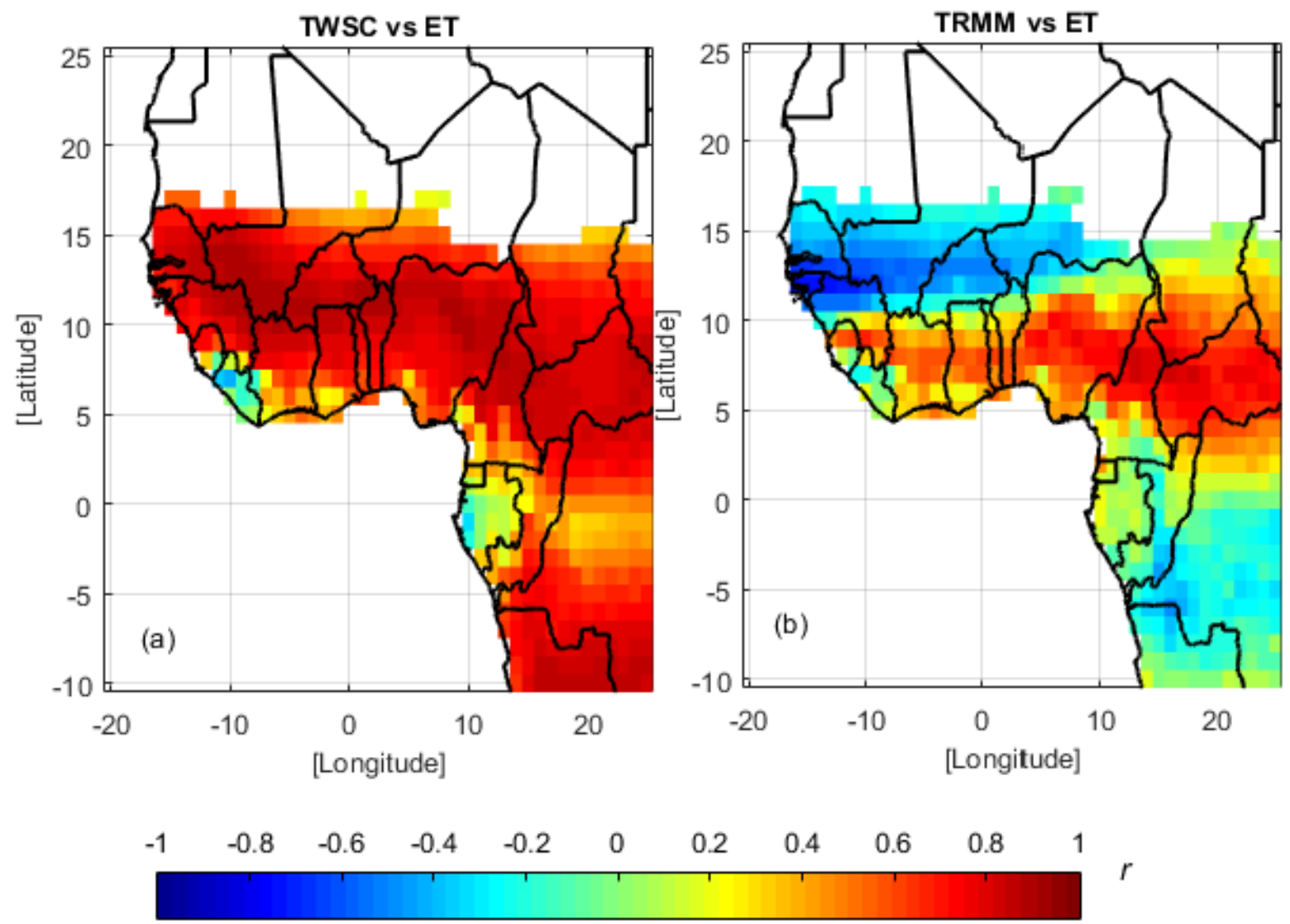

Figure 5: Spatial relationships of ET with TRMM-based precipitation and TWS change (TWSC) during a common period $(2002-2014)$. The observed relationships are based on Pearson correlation analysis between (a) TWSC and ET, and (b) TRMM-based precipitation with ET. 


\subsubsection{Spatial correlations of ET with TWSC and rainfall}

The correlation results of ET with TWSC and rainfall show that ET has strong association with TWSC over SSA (Fig. 5a) where the four leading modes of ET variability was observed (Fig. 2). Except for some few locations (e.g., Liberia, Garbon, Congo basin cuvette) where the associations are rather weak, the observed correlations between ET and TWSC are generally strong and more than 0.8 over large portions of SSA. Rainfall on the other hand is strongly correlated with ET over the whole of CAR and Western African countries (Fig. 5b) where the strongest variability in ET (28.1\%) was observed (IC1, Fig. 2). Although higher temperatures in the arid Sahel (Section 4.3) are bound to also impact on ET rates, strong correlations between ET and TWSC in the region (Fig. 5a) are indications ET may be more closely connected to moisture and water availability than with other drivers of its variability (e.g., humidity, land use change, wind speed, etc.). The observed association between GRACEderived TWSC and ET confirms that TWSC is a key water budget indicator that can be used to assess the state of available water resources in a given catchment. Moreover, the considerably strong ET-TWSC relationship over SSA presents TWSC as a useful tool in the monitoring of climate impacts on the variability of ET and water budget.

ET over the whole of CAR indicates a strong spatial consistency (i.e., positive correlation) with rainfall (Fig. 5b). In CAR, 22 vegetation types ranging from savannas, swamp forests, to other forest showed strong correlation with rainfall (Gond et al., 2013). Since CAR is predominantly characterised by natural vegetation and croplands, this strong positive ET correlation with rainfall will be expected. The CAR is an area of dense vegetation and rainfall is expected to correlate well with plant biomass as surface greenness is usually associated with wet conditions. Other natural vegetation areas in Cameroon, Nigeria, Ghana, Benin, and Ivory Coast (cf. Fig. 1b) also show strong positive distributions of correlation values between ET and rainfall. In the western Sahel region (i.e., parts of the Senegal, Volta, and Niger basinsFig. 1a) however, relatively strong negative correlations of ET with rainfall are observed in southern Mali, north-east Guinea Burkina Faso, Guinea-Bissau, southern Niger, Senegal, and Gambia while weak negative correlation is seen in the central part of Democratic Republic of Congo-DRC (Fig. 5b). It seems that these areas where ET is negatively correlated with rainfall are highly irrigated agricultural lands. An instance of this, is the southern Niger where rice irrigation is common, and relatively high annual water withdrawal per inhabitant (Mali, Senegal Niger, and Guinea) has been documented (Frenken, 2005). The inverse relationship between ET and rainfall in the DRC is modest in some locations and for the most parts weak. 
On the other side of SSA (i.e., in Eastern African countries especially Ethiopia, Nile Delta, and Uganda), Alemu et al. (2015) observed similar negative correlations between ET and rainfall in irrigated croplands, wetlands, and forests. Moreover, from the seasonal distribution of ET over SSA (see Section 4.3), it is noted that except for the wet seasons (i.e., the April-June and July-September period), ET values are extremely low in these Sahelian countries (i.e., Mali, Burkina Faso, Senegal, Gambia, and Guinea-Bissau) with observed negative ET-rainfall relationship. Low ET distribution is an indication of low soil water availability resulting from limited precipitation and restricted alimentation or water deficits. This necessitates irrigation in some areas since the main crop seasons occur during the January-March and OctoberDecember periods given the fact that rainfall is highly variable. The region is unarguably a rain-fed region, however, Frenken (2005) reported that about 2,619, 950 ha of land in the Sudano-Sahel area is under irrigation. In fact, for the entire SSA, they further reported an increasing trend of total water withdrawals (i.e., for a 10-year period) from $73.60 \mathrm{~km}^{3} / \mathrm{yr}$ in 1994 to $120.90 \mathrm{~km}^{3} / \mathrm{yr}$ in 2004 , with agricultural water use being the highest (i.e., $62.9 \mathrm{~km}^{3} / \mathrm{yr}$ in 1994 to $104.7 \mathrm{~km}^{3} / \mathrm{yr}$ in 2004), followed by domestic (i.e., $7.5 \mathrm{~km}^{3} / \mathrm{yr}$ in 1994 to $12.6 \mathrm{~km}^{3} / \mathrm{yr}$ in 2004) and industrial use (i.e., $3.2 \mathrm{~km}^{3} / \mathrm{yr}$ in 1994 to $3.6 \mathrm{~km}^{3} / \mathrm{yr}$ in 2004 ).
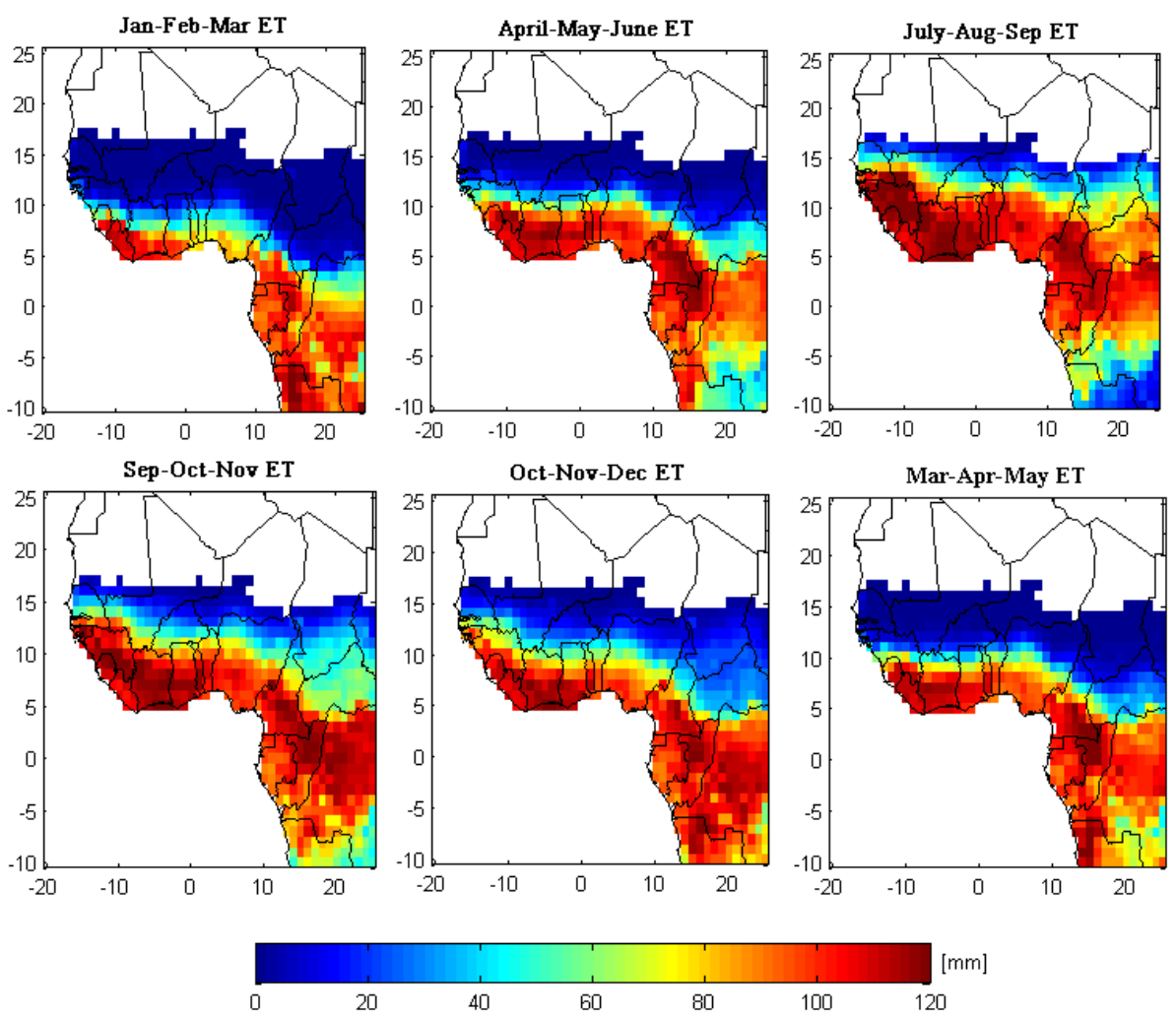

Figure 6: Seasonal spatial patterns of evapotranspiration over SSA using MODIS data for the period between 2000 and 2014. The zero ET values in the Sahara desert have been removed. 


\subsection{Evapotranspiration over SSA:synopsis and seasonal distribution}

In this section, the goal is to discuss the seasonal distribution of ET. More importantly we make efforts to understand the variable response of seasonal distribution of ET to land surface temperature, and other observed water fluxes in the SSA domain. This knowledge can provide a theoretical framework that could be used to advance hydrological science and improve our understanding of the land-atmosphere coupling in the region. The seasonal ET patterns were classified based on the seasonal rainfall patterns of the countries in SSA. For the countries above the Equator (i.e., Gulf of Guinea countries), the rainy seasons come during April-June and July-September period while the dry seasons are mostly during the January-March and October-December period. For the SSA equatorial countries (countries with equatorial climate along the Equator), the wet seasons come during March-April and September-November period. ET is low during the main crop seasons (Jan-March and October-December period) in the tropical countries and generally high during the mid crop seasons (March-May, April-June, and July-August) (Fig. 6) due to the presence of heavy rainfall, wet soils and transpiration from plants during those periods. In the high vegetation and canopy areas (Figs. 1b and 6) with high amplitudes of annual rainfall and TWS (Ndehedehe et al., 2016a), ET may be constrained basically by temperature, while in some of the semi arid Sahelian areas characterised by grasslands and shrubs, ET would be a function of available soil moisture, which usually is determined by rainfall. Notice that from Latitude $16^{\circ}$ or there about (the Sahara Desert), there are practically no fluxes (Fig. 6), the more reason why the ET-rainfall and ET-TWS relationships are non-existent in those areas (Fig. 5) probably due to extreme aridity and exceedingly high temperatures (Fig. 7). Although soil moisture and rainfall can be highly variable, most Sahelian areas are arid and water-limited ecosystems characterised by considerably low seasonal ET distribution (Fig. 6).

Further, it is observed that temperature is generally and relatively low in all seasons in the Congo basin especially the $\mathrm{DRC}$ with values ranging from $20^{\circ}-23^{\circ} \mathrm{C}$ (Fig. 7 ). The DRC is mostly characterised with dense moist forest, tree and woodland savanna, grasslands, and forests. That may possibly lead to the assumption that transpiration is the dominant ET component in this region (i.e., the DRC). Water loss through ET in this region should depend largely on the amount of foliage on the land surface not necessarily through evaporation. Moreover, the combined effect of intensive human activities (e.g., deforestation, land use change) and decline in seasonal and annual rainfall can sometimes lead to declines in ET. For instance, during the period of $2002-2011$, Alemu et al. (2015) observed over the Nile basin, negative 

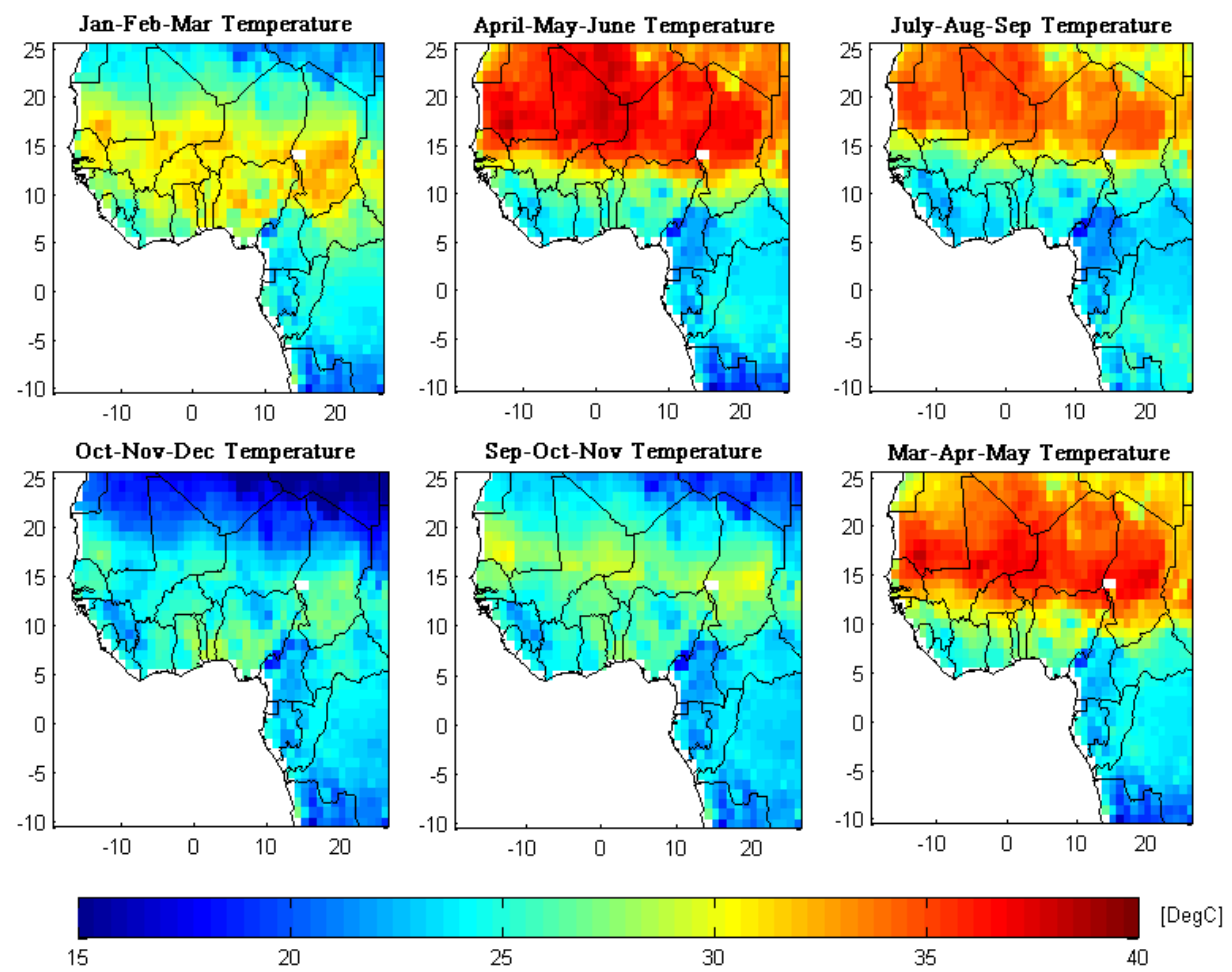

Figure 7: Seasonal land surface temperature patterns over SSA using GLDAS data for the period between 2000 and 2014 .

trends in ET that were associated with declines in rainfall and land degradation caused by human activities. The fact that sections of the Congo basin (especially the DRC) showed significant declines in ET, soil moisture, and TWS during the period of $2002-2014$ (Fig. 3a-d), besides confirming wide spread water deficits (Zhou et al., 2014) and intensification of the hydrological cycle (Huntington, 2006), may predispose and open up a leeway of greater loss of bio-diversity and ecosystem services in the region. This apparently could lead to a significant negative impact on the regional water cycle, water budget, agriculture, and the economy at large. However, the role of atmospheric relative humidity, deforestation, and climate teleconnections on the hydrological behaviour of the region remain pertinent questions that requires further research using a data-driven approach.

\subsection{The impacts of soil moisture deficits on evapotranspiration}

The impact of soil moisture deficits on ET dynamics is examined by analysing agricultural drought using long term CPC model soil moisture (1979 - 2013). Agricultural drought (insufficient water availability in the soil caused mostly by rainfall deficits, insufficient waterholding capacity in the soil's root zone, and high atmospheric demand, e.g., Marshall et al. (2012b)) over the Congo basin was investigated by computing a standardised soil moisture 

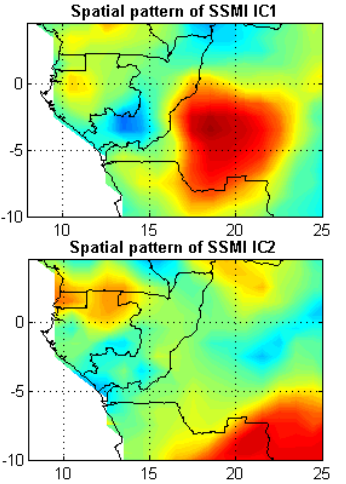

Spatial pattern of SSMI IC3
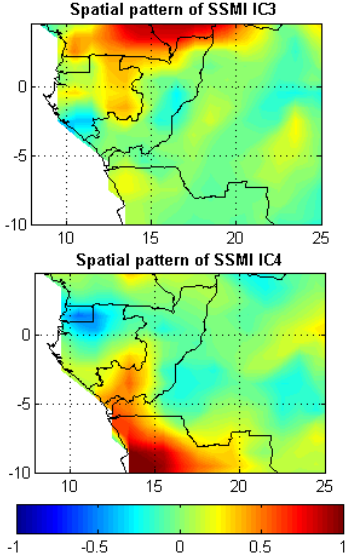
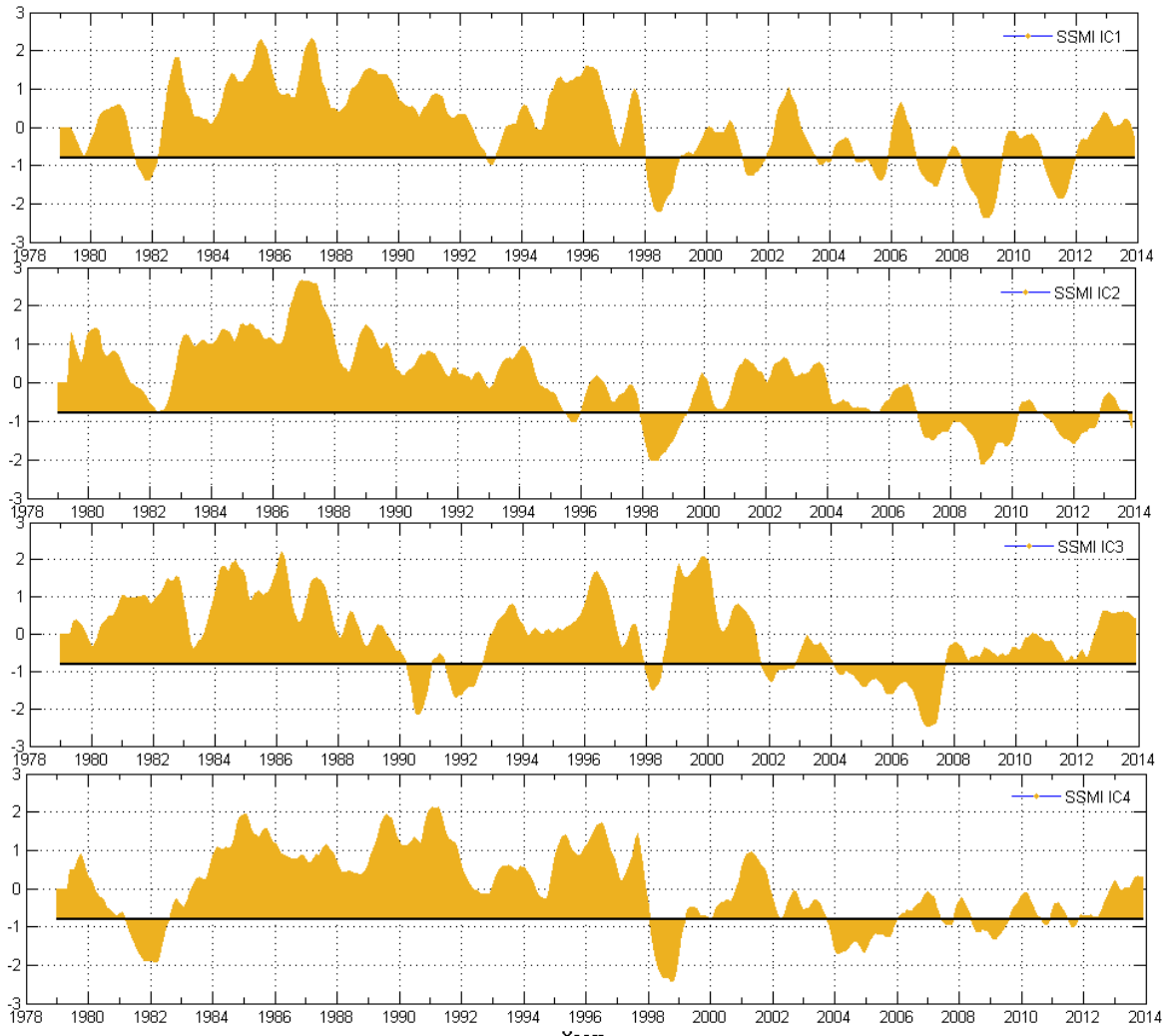

Figure 8: Spatio-temporal drought patterns of the Congo basin using 6-month gridded standardised soil moisture index (SSMI) values. SSMI values are computed using CPC soil moisture product for the period 19792014. Actual values for drought classification and categorisation with respect to McKee et al. (1993) description (Table 1) are jointly derived from the localised spatial drought patterns (right) and their corresponding temporal evolutions (left). The black solid line is drought threshold.

index (SSMI) based on a six month aggregation scale. Since soil moisture conditions respond to changes in precipitation on a short scale (Mishra and Singh, 2010), a soil moisture based drought index can provide the capability of monitoring drought and wet conditions suitable for agricultural applications. The results of the spatio-temporal drought analysis (Fig. 8) confirms that the observed soil moisture deficit in some parts of the Congo basin must have contributed to observed ET loss (Figs. 3a-c). From the temporal evolutions of SSMI (IC1-IC4, Fig. 8), hydrological conditions of the Congo basin were apparently better between 1982 and 1998 as opposed to the period between 2000 and 2014 when areas under droughts based on the classification in Table 1 were relatively high. The amplitudes of temporal SSMI patterns were mostly indicative of extreme wet conditions in the 1980s and 1990s while the period between 2000 and 2014 for the different zones (IC-IC4, Fig. 8) were generally characterised by deficit soil moisture conditions (when index falls below the zero mark) or drought conditions ranging from moderate to extreme (Table 1). Except for the CAR region where wet conditions 
continued unabated till 2001 (IC3, Fig. 8), generally, the preponderance of these extreme wet conditions ceased for other locations of the basin after 1997 (IC1 and IC4, Fig. 8) and 1995 (IC2, Fig. 8). In a study of global land evapotranspiration, Jung et al. (2010) observed global annual evapotranspiration increase between 1982 and 1997 that ceased after the El-Ninõ event of 1998. Especially over Africa, they attributed the observed declines in ET after this period to moisture deficits. Whereas the results in Fig. 8 indicating similar fluctuations in soil moisture conditions are rather consistent with the findings of Jung et al. (2010), it further emphasize the role of the Congo basin in regulating global climate.

In the central DRC (IC1, Fig. 8), soil moisture deficits are observed in 2005, $2007-2009$ and 2011. Notice that the southern DRC where ET went down (IC2, Fig. 2) is the catchment with longer drought duration (IC2, Fig. 8). Although with marked fluctuations, this southern DRC indicates a soil moisture deficit since 2006 up till 2014 consistent with observed decline in ET. The fact that ET responds and becomes restricted by soil moisture is well known (Jung et al., 2010; Marshall et al., 2012a). ET generally rely on soil moisture availability and net solar radiation, which largely depends on temperature. Considering the relatively low land surface temperature in much of the Congo basin in all seasons (Fig. 7), and the signficant decline in soil moisture (Fig. 3d), ET would definitely be restricted in this area of the Congo basin. Further, the periods during $2004-2007$ (IC3, Fig. 8) and $2004-2006$ (IC4, Fig. 8) also indicate moderate to severe drought conditions in the upper and lower (i.e., southern Congo and northern Angola) sub regions of Congo basin, respectively. Overall, the areas with ET declines in the Congo basin (Fig. 3) seem to have occurred in catchments with one of the longest duration in soil moisture deficits as can be seen in the extreme south of the basin (IC2, Fig. 8). To say the least, the observed hydrological footage is indicative of some sort of climatic shift and or acceleration of the water cycle that may impact on agricultural potentials. That is to say, decline in ET and soil moisture may proportionately impact negatively on crop yield. Marshall et al. (2012b) reported an instance of this in Kenya where a 1\% decline in ET resulted in a loss of $1.5 \%$ in maize yield. While it is true that the availability of soil water is critical at every stage of crop development, Marshall et al. (2012b) further stressed the extreme sensitivity of crops to soil moisture especially during their reproductive stages. On the whole, extreme climate conditions (e.g., droughts) impact negatively on agriculture leading to reduced annual crop yield. In this study, soil moisture data was used to monitor soil water deficit, which is useful in agricultural applications. However, integrating ET-based index and other hydrological quantities (e.g., precipitation and soil moisture) in future studies 
could improve agricultural drought monitoring, forecasting changes in forest growth/crop yield, and characterising the reproductive phase of crop growth. The seeming realities of drought conditions and declines in water fluxes calls for an inclusive and in-depth assessment of the Congo basin's terrestrial hydrology. It is particularly essential that new approaches, such as integrating science and policy solutions for sustainability in agriculture and water resources over the Congo basin be considered in future studies.

\section{Conclusions}

In this study, the dynamics of ET over large proportions of SSA is analysed using multivariate techniques and Man-Kendall's statistics. Essential to our analysis is the assessment of spatial and temporal dynamics of ET in relation to soil moisture deficits. Results from the study show that the leading four modes of variability in ET stretches from the Sudano-Sahel region to the Congo basin and accounts for about $90 \%$ of the total variability. These regions are predominantly savannas, forests, grasslands, and agricultural biomes and also known to be characterised by strong variability in annual and seasonal rainfall. Interestingly, the strongest variability of ET (28.1\%) was found in areas where rainfall was well correlated (positive) with ET. Apparently, ET indicated strong spatial relationship with TWSC over much of SSA where all the four leading ET modes where localised. The strong ET-TWSC relationship suggests the potential of GRACE-derived TWSC as an essential water budget indicator and tool that could support the monitoring of climate impacts on the variability of ET and water budget in the region. Spatial variations of monthly grids of ET trends over much of the Congo basin showed significant declines while it increased significantly over the whole of CAR and some sections of the Sahel region (excluding western Sahel). But during the April-October period when the preponderance of rainfall is observed over much of SSA, the spatial variations of ET trends are much stronger and widespread as opposed to the November-March period when rainfall is usually restricted. The spatial distribution of these trends, be it all monthly time series or seasonal, were found to be somewhat consistent with soil moisture trends, however, not in all locations (e.g., Guinea, Sierra Leone, and southern Nigeria, etc.) and may be partly caused by inconsistent trends in temperature and rainfall.

The results of multivariate drought analysis confirm that the extensive ET losses in the Congo basin was largely induced by soil moisture deficits/droughts in the region (i.e., between 1998 and 2014), confirming the role of soil moisture as a major driver in the ET process. The apparent realities of such water deficit conditions (i.e., relative to the $1982-1997$ period) and 
declines in water fluxes of the Congo basin is a clarion call for the hydrologic community to adopt an inclusive and in-depth assessment of the basin's terrestrial hydrology. Regarding our understanding of the water needs of irrigated agricultural landscapes and ecosystems in relation to climate change, it is particularly essential that new options and strategies, such as the joint use of composite ET-based index and other hydrological quantities (e.g., netprecipitation) be incorporated in future studies to provide more information on the impacts of climate variability on ET dynamics and how it influence water availability. Generally, the findings of this study could be fundamental cornerstones that will foster such decisions for the data-limited African sub-region. 
Acknowledgments

Christopher E. Ndehedehe is grateful to Curtin University for the funding received through the CSIRS programme, which supported his research during the period when part of this study was undertaken. The Authors are also grateful to CSR, NOAA, and NASA for all the data used in this study. 


\section{References}

A, G., Velicogna, I., Kimball, J. S., and Kim, Y. (2015). Impact of changes in GRACE derived terrestrial water storage on vegetation growth in Eurasia. Environmental Research Letters, 10(12):124024.

Abiy, A. Z. and Melesse., A. (2017). Evaluation of watershed scale changes in groundwater and soil moisture storage with the application of $\{$ GRACE $\}$ satellite imagery data. CATENA, 153:50 - 60. doi:10.1016/j.catena.2017.01.036.

Abtew, W. and Melesse, A. (2013). Climate change and evapotranspiration. In Evaporation and Evapotranspiration: Measurements and Estimations, pages 197-202. doi:10.1017/97894-007-4737-1_13.

Agutu, N., Awange, J., Zerihun, A., Ndehedehe, C., Kuhn, M., and Fukuda, Y. (2017). Assessing multi-satellite remote sensing, reanalysis, and land surface models' products in characterizing agricultural drought in East Africa. Remote Sensing of Environment, 194(0):287302. doi:10.1016/j.rse.2017.03.041.

Ahmed, M., Sultan, M., J.Wahr, and Yan, E. (2014). The use of GRACE data to monitor natural and anthropogenic induced variations in water availability across Africa. Earth Science Reviews, 136:289-300. doi:10.1016/j.earscirev.2014.05.009.

Alemu, H., Kaptué, A. T., Senay, G. B., Wimberly, M. C., and Henebry, G. M. (2015). Evapotranspiration in the Nile Basin: identifying dynamics and drivers, 2002-2011. Water, 7:4914-4931. doi:10.3390/w7094914.

Andam-Akorful, S. A., Ferreira, V. G., Awange, J. L., Forootan, E., and He, X. F. (2015). Multi-model and multi-sensor estimations of evapotranspiration over the Volta Basin, West Africa. International Journal of Climatology, 35(10):3132-3145. doi:10.1002/joc.4198.

Awange, J., Forootan, E., Kuhn, M., Kusche, J., and Heck, B. (2014). Water storage changes and climate variability within the Nile Basin between 2002 and 2011. Advances in Water Resources, 73(0):1 - 15. doi:10.1016/j.advwatres.2014.06.010.

Boergens, E., Rangelova, E., Sideris, M. G., and Kusche, J. (2014). Assessment of the capabilities of the temporal and spatiotemporal ICA method for geophysical signal separation in GRACE data. Journal of Geophysical Research Solid Earth, 119:4429-4447,. doi:10.1002/2013JB010452. 
Cao, G., Han, D., and Song, X. (2014). Evaluating actual evapotranspiration and impacts of groundwater storage change in the North China Plain. Hydrological Processes, 28(4):17971808. doi:10.1002/hyp.9732.

Cardoso, J. F. (1999). High-Order contrasts for Independent Component Analysis. Neural Computation, 11:157-192.

Cardoso, J. F. and Souloumiac, A. (1993). Blind beamforming for non-gaussian signals. IEE Proceedings, 140(6):362-370.

Descroix, L., Mahé, G., Lebel, T., Favreau, G., Galle, S., Gautier, E., Olivry, J.-C., Albergel, J., Amogu, O., Cappelaere, B., Dessouassi, R., Diedhiou, A., Breton, E. L., Mamadou, I., and Sighomnou, D. (2009). Spatio-temporal variability of hydrological regimes around the boundaries between Sahelian and Sudanian areas of West Africa: A synthesis. Journal of Hydrology, 375(12):90-102. doi:10.1016/j.jhydrol.2008.12.012.

Fan, Y. and Dool, H. V. (2004). Climate prediction center global monthly soil moisture data set at $0.5^{\circ}$ resolution for 1948 to present. Journal Of Geophysical Research, 109:D10102. doi:10.1029/2003JD004345.

Farahmand, A. and AghaKouchak, A. (2015). A generalized framework for deriving nonparametric standardized drought indicators. Advances in Water Resources, (76):140-145. doi:/10.1016/j.advwatres.2014.11.012.

Fenoglio-Marc, L., Rietbroek, R., Grayek, S., Becker, M., Kusche, J., and Stanev, E. (2012). Water mass variation in the Mediterranean and Black Seas. Journal of Geodynamics, 5960:168 182.

Ferreira, V. and Asiah, Z. (2015). An investigation on the closure of the water budget methods over Volta Basin using multi-satellite data. International Association of Geodesy Symposia. doi:10.1007/1345-2015-137.

Frappart, F., Ramillien, G., Leblanc, M., Tweed, S. O., Bonnet, M.-P., and Maisongrande, P. (2011). An independent component analysis filtering approach for estimating continental hydrology in the GRACE gravity data. Remote Sensing of Environment, 115(1):187 - 204. doi:doi.org/10.1016/j.rse.2010.08.017.

Frenken, K. (2005). Irrigation in Africa in figures. FAO Land and Water Development Division, 
89 pp. Retrieved from:ftp://ftp.fao.org/agl/aglw/docs/wr29-eng.pdf, Accessed 22 January, 2016 .

Gond, V., Fayolle, A., Pennec, A., Cornu, G., Mayaux, P., Camberlin, P., Doumenge, C., Fauvet, N., and Gourlet-Fleury, S. (2013). Vegetation structure and greenness in central africa from modis multi-temporal data. Philosophical Transactions of the Royal Society of London B: Biological Sciences, 368(1625). doi:10.1098/rstb.2012.0309.

Gowda, P. H., Chavez, J. L., Colaizzi, P. D., Evett, S. R., Howell, T. A., and Tolk, J. A. (2008). ET mapping for agricultural water management: present status and challenges. Irrigation Science, 26(3):223-237. doi:10.1007/s00271-007-0088-6.

Han, S., Xu, D., and Yang, Z. (2017). Irrigation-induced changes in evapotranspiration demand of awati irrigation district, Northwest China: weakening the effects of water saving? Sustainability, 9(9). doi:10.3390/su9091531.

Hannachi, A., Jolliffe, I. T., and Stephenson, D. B. (2007). Empirical orthogonal functions and related techniques in atmospheric science: A review. International Journal Of Climatology, 27:11191152. doi:10.1029/96JC00922.

Hanson, R. L. (2013). Evapotranspiration and droughts. U. S. Geological Survey. Retrieved from:http://geochange.er.usgs.gov/sw/changes/natural/et/. Accessed 7 January, 2016.

Hao, Z. and AghaKouchak, A. (2014). A nonparametric multivariate multi-index drought monitoring framework. Journal of Hydrometeorology, 15(1):89-101. doi:10.1175/JHM-D12-0160.1.

Hendricks, J. R., Leben, R. R., Born, G. H., and Koblinsky, C. J. (1996). Empirical orthogonal function analysis of global TOPEX/POSEIDON altimeter data and implications for detection of global sea level rise. Journal of Geophysical Research, 101(C6):14131 - 14145. doi:10.1029/96JC00922.

Hua, W., Zhou, L., Chen, H., Nicholson, S. E., Raghavendra, A., and Jiang, Y. (2016). Possible causes of the Central Equatorial African long-term drought. Environmental Research Letters, 11(12):124002. doi:10.1088/1748-9326/11/12/124002.

Huntington, T. G. (2006). Evidence for intensification of the global water cycle: Review and synthesis. Journal of Hydrology, 319(14):83 - 95. doi:10.1016/j.jhydrol.2005.07.003. 
Jung, M., Reichstein, M., Ciais, P., Seneviratne, S. I., Sheffield, J., Goulden, M. L., Bonan, G., Cescatti, A., Chen, J., Jeu, R. d., Dolman, A. J., Eugster, W., Gerten, D., Gianelle, D., Gobron, N., Heinke, J., Kimball, J., Law, B. E., Montagnani, L., Mu, Q., Mueller, B., Oleson, K., Papale, D., Richardson, A. D., Roupsard, O., Running, S., Tomelleri, E., Viovy, N., Weber, U., Williams, C., Wood, E., Zaehle, S., and Zhang, K. (2010). Recent decline in the global land evapotranspiration trend due to limited moisture supply. Nature, 467(7318):951-954.

Kendall, M. G. (1970). Rank correlation methods. Griffin, London, (4th edition). UK.

Kumar, R., Musuuza, J. L., Loon, A. F. V., Teuling, A. J., Barthel, R., Broek, J. T., Mai, J., Samaniego, L., and Attinger, S. (2015). Multiscale evaluation of the standardized precipitation index as a groundwater drought indicator. Hydrology and Earth System Sciences, 12:74057436. doi:10.5194/hessd-12-7405-2015.

Kummerow, C., Simpson, J., Thiele, O., Barnes, W., Chang, A. T. C., Stocker, E., Adler, R. F., Hou, A., Kakar, R., Wentz, F., Ashcroft, P., Kozu, T., Hong, Y., Okamoto, K., Iguchi, T., Kuroiwa, H., Im, E., Haddad, Z., Huffman, G., Ferrier, B., Olson, W. S., Zipser, E., Smith, E. A., Wilheit, T. T., North, G., Krishnamurti, T., and Nakamura, K. (2000). The status of the Tropical Rainfall Measuring Mission (TRMM) after two years in orbit. Journal of Applied Meteorology, 39(12):1965-1982. doi:10.1175/1520-0450(2001)040¡1965:TSOTTR ¿2.0.CO;2.

Landerer, F. W. and Swenson, S. C. (2012). Accuracy of scaled GRACE terrestrial water storage estimates. Water Resources Research, 48(4):W04531. doi:10.1029/2011WR011453.

Li, Y., Huang, C., Hou, J., Gu, J., Zhu, G., and Li, X. (2017). Mapping daily evapotranspiration based on spatiotemporal fusion of ASTER and MODIS images over irrigated agricultural areas in the Heihe River Basin, Northwest China. Agricultural and Forest Meteorology, 244-245(Supplement C):82 - 97. doi:10.1016/j.agrformet.2017.05.023.

Liu, M., Tian, H., Chen, G., Ren, W., Zhang, C., and Liu, J. (2008). Effects of land-use and land-cover change on evapotranspiration and water yield in China during 1900-20001. Journal of the American Water Resources Association, 44(5):1193-1207. 10.1111/j.17521688.2008.00243.x.

Liu, Y., Zhuang, Q., Chen, M., Pan, Z., Tchebakova, N., Sokolov, A., Kicklighter, D., Melillo, J., Sirin, A., Zhou, G., He, Y., Chen, J., Bowling, L., Miralles, D., and Parfenova, E. (2013). 
Response of evapotranspiration and water availability to changing climate and land cover on the Mongolian Plateau during the 21st century. Global and Planetary Change, 108:85-99. doi:10.1016/j.gloplacha.2013.06.008.

Liu, Y., Zhuang, Q., Pan, Z., Miralles, D., Tchebakova, N., Kicklighter, D., Chen, J., Sirin, A., He, Y., Zhou, G., and Melillo, J. (2014). Response of evapotranspiration and water availability to the changing climate in northern eurasia. Climatic Change, 126(3-4):413427.

Long, D., Longuevergne, L., and Scanlon, B. R. (2014). Uncertainty in evapotranspiration from land surface modeling, remote sensing, and GRACE satellites. Water Resources Research, 50(2):1131-1151.

Machiwal, D. and Jha, M. K. (2012). Hydrological time series: theory and practice. Springer. India.

Mann, H. B. (1945). Nonparametric tests against trend. Econometrica, 13(3):245-259. doi:10.2307/1907187.

Marshall, M., Funk, C., and Michaelsen, J. (2012a). Examining evapotranspiration trends in Africa. Climate Dynamics,, 38(9-10):1849-1865. doi:10.1007/s00382-012-1299-y.

Marshall, M., Tu, K., Funk, C., Michaelsen, J., Williams, P., Williams, C., Ardö, J., Boucher, M., Cappelaere, B., de Grandcourt, A., Nickless, A., Nouvellon, Y., Scholes, R., and Kutsch, W. (2013). Improving operational land surface model canopy evapotranspiration in africa using a direct remote sensing approach. Hydrology and Earth System Sciences, 17(3):10791091. doi:10.5194/hess-17-1079-2013.

Marshall, M. T., Funk, C., and Michaelsen, J. (2012b). Agricultural drought monitoring in Kenya using evapotranspiration derived from remote sensing and reanalysis data, in remote sensing of drought: Innovative monitoring approaches. CRC Press, pages 169-194. doi:10.1201/b11863-1110.1201/b11863-11.

McKee, T. B., Doeskin, N. J., and Kieist, J. (1993). The relationship of drought frequency and duration to time scales. Conference on Applied Climatology, American Meteorological Society,Boston, Massachusetts, pages 179-184. Retrieved from:www.ccc.atmos.colostate.edu/relationshipofdroughtfrequency.pdf. Accessed 27 June, 2014. 
Mishra, A. K. and Singh, V. P. (2010). A review of drought concepts. Journal of Hydrology, 391:202-216. doi:10.1016/j.jhydrol.2010.07.012.

Mu, Q., Zhao, M., and Running, S. W. (2011). Improvements to a MODIS global terrestrial evapotranspiration algorithm. Remote Sensing of Environment, 115(8):1781 - 1800. doi:10.1016/j.rse.2011.02.019.

Ndehedehe, C., Awange, J., Agutu, N., Kuhn, M., and Heck, B. (2016a). Understanding changes in terrestrial water storage over West Africa between 2002 and 2014. Advances in Water Resources, 88:211-230. doi:10.1016/j.advwatres.2015.12.009.

Ndehedehe, C. E., Agutu, N. O., and Okwuashi, O. (2018a). Is terrestrial water storage a useful indicator in assessing the impacts of climate variability on crop yield in semi-arid ecosystems? Ecological Indicators, 88C:51-62. doi:10.1016/j.ecolind.2018.01.026.

Ndehedehe, C. E., Agutu, N. O., Okwuashi, O. H., and Ferreira, V. G. (2016b). Spatio-temporal variability of droughts and terrestrial water storage over Lake Chad Basin using independent component analysis. Journal of Hydrology, 540:106-128. doi:10.1016/j.jhydrol.2016.05.068.

Ndehedehe, C. E., Awange, J., Kuhn, M., Agutu, N., and Fukuda, Y. (2017a). Analysis of hydrological variability over the Volta river basin using in-situ data and satellite observations. Journal of Hydrology: Regional studies, 12:88-110. doi:10.1016/j.ejrh.2017.04.005.

Ndehedehe, C. E., Awange, J., Kuhn, M., Agutu, N., and Fukuda, Y. (2017b). Climate teleconnections influence on West Africa's terrestrial water storage. Hydrological Processes, 31(18):3206-3224. doi: 10.1002/hyp.11237.

Ndehedehe, C. E., Awange, J. L., Agutu, N. O., and Okwuashi, O. (2018b). Changes in hydro-meteorological conditions over tropical West Africa (1980 - 2015) and links to global climate. Global and Planetary Change, 162:321-341. doi:10.1016/j.gloplacha.2018.01.020.

Ndehedehe, C. E., Awange, J. L., Corner, R., Kuhn, M., and Okwuashi, O. (2016c). On the potentials of multiple climate variables in assessing the spatio-temporal characteristics of hydrological droughts over the Volta Basin. Science of the Total Environment, 557-558:819837. doi:10.1016/j.scitotenv.2016.03.004.

Opoku-Duah, S., Donoghue, D., and Burt, T. P. (2008). Intercomparison of evapotranspiration 
over the savannah Volta Basin in West Africa using remote sensing data. Sensors, 8(4):27362761. doi:10.3390/s8042736.

Polhamus, A., Fisher, J. B., and Tu, K. P. (2013). What controls the error structure in evapotranspiration models? Agricultural and Forest Meteorology, 169:12-24. doi:10.1016/j.agrformet.2012.10.002.

Rodell, M., Houser, P. R., Jambor, U., Gottschalck, J., Mitchell, K., Meng, K., Arsenault, C. J., Cosgrove, B., Radakovich, J., Bosilovich, M., Entin, J. K., Walker, J. P., Lohmann, D., and Toll, D. (2004). The global land data assimilation system. Bulletin of American Meteorological Society, 85(3):381-394. doi:10.1175/BAMS-85-3-381.R.

Schüttemeyer, D., Schillings, C., Moene, A. F., and Bruin, H. A. R. D. (2007). Satellite-based actual evapotranspiration over drying semiarid terrain in West Africa. Journal Of Applied Meteorology And Climatology, 46:97-111. doi:10.1175/JAM2444.1.

Sen, P. K. (1968). Estimates of the regression coefficient based on Kendall's Tau. Journal of the American Statistical Association, 63(324):1379-1389. doi:10.1080/01621459.1968.10480934.

Shukla, S. and Wood, A. W. (2008). Use of a standardized runoff index for characterizing hydrologic drought. Geophysical Research Letters, 35(2):L02405. 10.1029/2007GL032487.

Song, L., Zhuang, Q., Yin, Y., Zhu, X., and Wu, S. (2017). Spatio-temporal dynamics of evapotranspiration on the Tibetan Plateau from 2000 to 2010. Environmental Research Letters, 12(1):014011.

Tadesse, T., Senay, G. B., Berhan, G., Regassa, T., and Beyene, S. (2015). Evaluating a satellite-based seasonal evapotranspiration product and identifying its relationship with other satellite-derived products and crop yield: A case study for Ethiopia. International Journal of Applied Earth Observation and Geoinformation, 40(Supplement C):39 - 54 . doi:10.1016/j.jag.2015.03.006.

Tapley, B., Bettadpur, S., Watkins, M., and Reigber, C. (2004). The Gravity Recovery and Climate Experiment: Mission overview and early results. Geophysical Research Letters, 31:1-4. doi:10.1029/ 2004GL019920.

Thiemig, V., Rojas, R., Zambrano-Bigiarini, M., Levizzani, V., and Roo, A. D. (2012). Validation of satellite-based precipitation products over sparsely gauged African river basins. Journal of Hydrometeorology, 13(6):1760-1783. 
Wahr, J., Molenaar, M., and Bryan, F. (1998). Time variability of the Earth's gravity field: Hydrological and oceanic effects and their possible detection using GRACE. Journal of Geophysical Research-Solid Earth, 103(B12):30205-30229. doi:10.1029/98jb02844.

Wouters, B., Bonin, J. A., Chambers, D. P., Riva, R. E. M., Sasgen, I., and Wahr, J. (2014). GRACE, time-varying gravity, Earth system dynamics and climate change. Reports on Progress in Physics, 77(11):116801. doi:10.1088/0034-4885/77/11/116801.

Yang, Y., Long, D., Guan, H., Scanlon, B. R., Simmons, C. T., Jiang, L., and Xu, X. (2014). GRACE satellite observed hydrological controls on interannual and seasonal variability in surface greenness over mainland Australia. Journal of Geophysical Research: Biogeosciences, 119(12):2245-2260. doi:10.1002/2014JG002670.

Zhou, L., Tian, Y., Myneni, R. B., Ciais, P., Saatchi, S., Liu, Y. Y., Piao, S., Chen, H., Vermote, E. F., Song, C., and Hwang, T. (2014). Widespread decline of congo rainforest greenness in the past decade. Nature, 509(7498):86-90. doi:10.1038/nature13265.

Ziehe, A. (2005). Blind source separation based on joint diagonalization of matrices with applications in biomedical signal processing. PhD thesis, Universitat Potsdam. Retrieved from:http://en.youscribe.com/catalogue/reports-and-theses/knowledge/blindsource-separation-based-on-joint-diagonalization-of-matrices-1424347. Accessed 15 May 2015.

Zou, M., Niu, J., Kang, S., Li, X., and Lu, H. (2017). The contribution of human agricultural activities to increasing evapotranspiration is significantly greater than climate change effect over heihe agricultural region. Scientific Reports, 7(8805):1-14. doi:10.1038/s41598-01708952-5. 